\title{
PERENCANAAN MODEL DESAIN KOLAM TAMBAK INTENSIF KABUPATEN PROBOLINGGO
}

\author{
Jadfan Sidqi Fidari ${ }^{1}$, Maftuch $^{2}$, Mohammad Bisri ${ }^{1}$ \\ ${ }^{1}$ Jurusan Teknik Pengairan, Fakultas Teknik Universitas Brawijaya \\ ${ }^{2}$ Program Studi Budidaya Perairan, Fakultas Perikanan dan Ilmu Kelautan Universitas Brawijaya \\ e-mail : jadfan@ub.ac.id
}

\begin{abstract}
ABSTRAK : Probolinggo merupakan salah satu wilayah dengan potensi budidaya perikanan yang cukup tinggi. Hasil produksi budidaya perikanan cukup tinggi ditunjang oleh beberapa faktor antara lain benih, kondisi topografi alam, kondisi hidrologis dan desain kawasan. Dengan menggunakan fasilitas pada Laboratorium Perikanan Air Payau dan Laut Probolinggo dengan lahan seluas 5285,29 m2 dilakukan model perencanaan desain kolam dan manajemen air untuk produksi udang.

Metode yang dipergunakan adalah analisa hidrologi dan analisa kekuatan material timbunan terhadap model kolam yang dibuat. Model kolam yang dibuat terbagi menjadi 4 bagian, bagian pembenihan; pendederan; sirkulasi; dan ipal. Parameter yang dipergunakan sebagai dasar tingkat keberhasilan adalah besaran produksi dari budidaya.
\end{abstract}

Kata kunci : Kolam Ikan, Desain Model, Budidaya, Manajemen air

\begin{abstract}
Probolinggo is one of the areas with high potential of fishery cultivation. The production of aquaculture is quite high supported by several factors such as seeds, natural topography conditions, hydrological conditions and regional design. By using the facilities at the Brackishwater and Marine Fisheries Laboratory of Probolinggo with a land area of $1.005 \mathrm{~m} 2$ model of planning design ponds and water system for shrimp production.

The method used is the hydrological analysis and the material strength analysis of embankment on the pond model created. The pool model is divided into 4 parts, the seeding section; pendederan; circulation; and ipal. Parameters used as the basis of success rate is the production quantity of the cultivation.
\end{abstract}

Key words : Fishpond, Model Design, Cultivation, Water Management

Probolinggo merupakan daerah pesisir di wilayah Jawa Timur dengan potensi perikanan yang sangat besar. Komoditas perikanan merupakan komoditas dengan nilai ekonomi yang cukup tinggi. Potensi lain dari daerah probolinggo adalah pertambakan udang dengan jenis udang yang digunakan adalah Udang Vaname. Udang Vaname merupakan komoditas udang dengan tingkat budidaya dengan resiko yang cukup tinggi.

Tingginya faktor resiko pada tambak udang adalah sistem budidaya udang, disamping sistem budidaya, lokasi tambak dengan kondisi terbuka, tentunya menambah besar resiko sistem pertambakan disamping juga banyak permasalahan yang terjadi pada lokasi. Permasalahan yang timbul dapat berupa penyakit, sosial-ekonomi, dan kondisi geografis lokasi studi.

Berdasarkan hal tersebut maka kajian ini berupaya untuk mengatur sirkulasi tata air tambak udang dan membuat ekosistim buatan untuk model pembiakan udang dengan metode intensif.

\section{BAHAN DAN METODE}

Bahan dan metode yang dipergunakan dalam penelitian ini meliputi antara lain:

1. Bahan 
Analisa yang dilakukan memerlukan data antara lain:
a. Data pasang surut
b. Peta topografi
c. Layout jaringan
d. Data kualitas air untuk udang

2. Metode
a. Survei

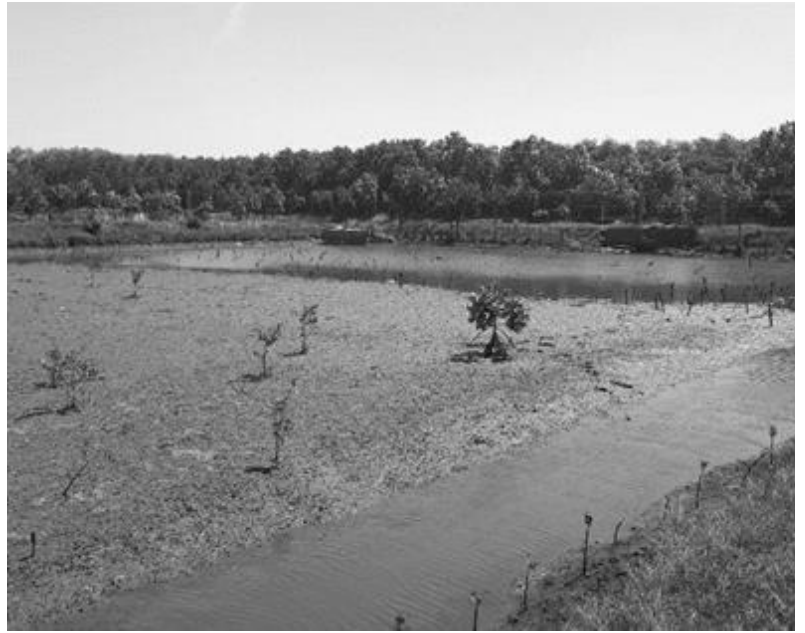

Gambar 1. Luasan Petakan Tambak Eksisiting Sumber: Dokumentasi

Pada tahapan ini dilakukan survei untuk penentuan lokasi dan rencana awal untuk petakan tambak. Lokasi berada di daerah Kota Probolinggo dengan koordinat $7^{\circ} 44^{\prime} 30.03$ "S dan $113^{\circ} 13^{\prime} 58.68$ "E.

b. Analisa Kebutuhan Air

Perhitungan kebutuhan air untuk irigasi pertambakan berdasarkan yang diberikan oleh FAO dapat dilihat pada persamaan sebagai berikut:

$$
Q=\frac{a \cdot h}{t . \frac{(1-\% \text { kehilangan })}{100}}
$$

Dimana:

Q = Kebutuhan debit $\left(\mathrm{m}^{3} / \mathrm{dt}\right)$

$\mathrm{t} \quad=$ Waktu yang diperlukan untuk pengisian kolam tambak (detik)

$\mathrm{h} \quad=$ Ketinggian untuk operasi (m)

a $\quad=$ Luas kolam $\left(\mathrm{m}^{2}\right)$

c. Analisa sirkulasi air

Sebagai perencanaan tahap awal maka dipilih alternatif Inlet dan Outlet. Jalu Inlet dipergunakan sebagai sumber air utama untuk komoditas udang, sedangkan jalur outlet merupakan bagian drainasi untuk pembuangan air dari kolam. Detail alternatif dapat dilihat pada Gambar 2 dan Gambar 3.



Gambar 2. Alternatif pemilihan alternatif inlet dan Outlet

Sumber: GoogleEarth Image@ 2017 CNES/ Airbus 


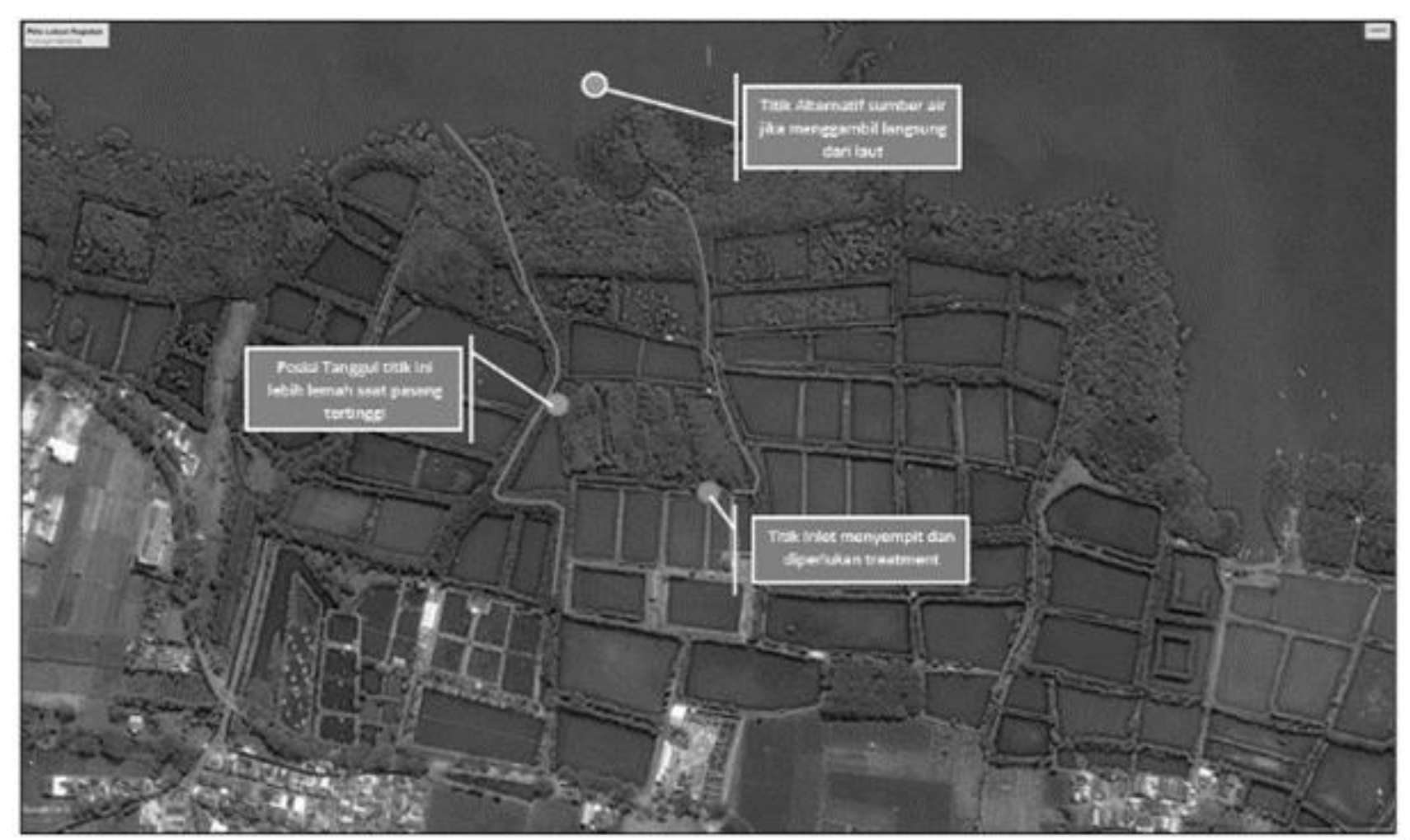

Gambar 3. Alternatif pemilihan alternatif inlet dan Outlet

Sumber: GoogleEarth Image@ 2017 CNES/ Airbus

d. Desain tanggul dan kolam

H. R. Rabanal (1983) dalam fisheries and Aquaculture FAO memberikan persyaratan untuk desain kolam pertambakan seperti yang ditunjukkan pada gambar 4 .

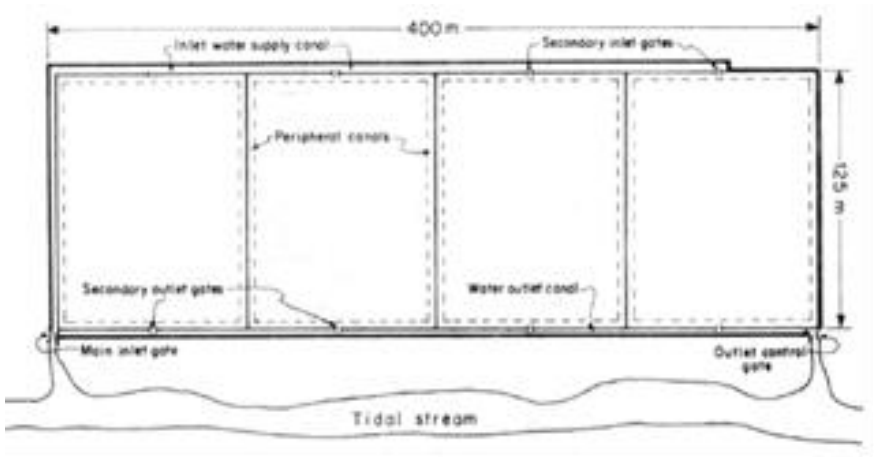

Gambar 4. Desain Petakan kolam untuk monoakuakultur

Sumber: H. R. Rabanal (1983) fisheries and Aquaculture, FAO

Dalam anjuran yang dipersyaratkan untuk budidaya udang, minimal dalam kawasan harus terdapat 4 bagian kolam; yaitu kolam untuk bagian pembenihan; pendederan; sirkulasi; dan ipal.
Dalam model ini air yang keluar dari kolam pertambakan harus memenuhi baku mutu air sungai pada bagian muara.

konsentrasi zat organik terlarut dipersyaratkan seminimal mungkin agar tidak terjadi perubahan ekosistem di luar petakan pertambakan.

Desain tanggul yang nantinya digunakan sebagai pemisah (perimeter) antar kolam dan sebagai pembatas kolam dengan wilayah laut mengikuti ketentuan sebagai berikut:

Tabel 1. Kriteria Luasan dan Proporsi

Pembagian Kolam tambak

\begin{tabular}{|c|l|l|}
\hline No. & \multicolumn{1}{|c|}{ Keterangan } & $\begin{array}{c}\text { Kriteria Luasan } \\
\text { Kolam }\end{array}$ \\
\hline 1 & Kolam Aklamatisasi & $4-8 \mathrm{~m}^{2}$ \\
\hline 2 & Kolam Pembenihan & $1 \%$ luasan \\
\hline 3 & Kolam Transisi & $10 \%$ luasan total \\
\hline 4 & Kolam Produksi & $80 \%$ luasan total \\
\hline 5 & $\begin{array}{l}\text { Kolam Permanen } \\
\text { (dengan pintu) }\end{array}$ & $\begin{array}{l}1,5 \% \text { luasan } \\
\text { total }\end{array}$ \\
\hline 6 & $\begin{array}{l}\text { Kolam penumbuhan } \\
\text { makanan }\end{array}$ & $7 \%$ luasan total \\
\hline
\end{tabular}

Sumber: H. R. Rabanal (1983) fisheries and Aquaculture FAO 
Tabel 2. Kriteria Desain Tanggul Kolam Tambak

\begin{tabular}{|c|c|c|c|c|c|c|}
\hline \multirow{2}{*}{\begin{tabular}{c} 
Construction height of $\begin{array}{c}|c| \\
\text { dike (m) }\end{array}$ \\
\cline { 2 - 7 }
\end{tabular}} & \multicolumn{3}{|c|}{ Top width } & \multicolumn{3}{c|}{ Side slopes 2:1 } \\
\cline { 2 - 7 } & $1 \mathrm{~m}$ & $2 \mathrm{~m}$ & $3 \mathrm{~m}$ & $1 \mathrm{~m}$ & $2 \mathrm{~m}$ & $3 \mathrm{~m}$ \\
\hline 0.5 & 0.8 & 1.3 & 1.8 & 1.0 & 1.5 & 2.0 \\
\hline 1.0 & 2.5 & 3.5 & 4.5 & 3.0 & 4.0 & 5.0 \\
\hline 1.5 & 5.0 & 6.5 & 8.0 & 6.0 & 7.5 & 9.0 \\
\hline 2.0 & 8.0 & 10.0 & 12.0 & 10.0 & 12.0 & 14.0 \\
\hline 2.5 & 12.0 & 14.5 & 17.0 & 15.0 & 17.5 & 20.0 \\
\hline 3.0 & 16.5 & 19.5 & 22.5 & 21.0 & 24.0 & 27.0 \\
\hline
\end{tabular}

Sumber: Cruz, C.R Dela (2015)

e. Perbandingan rasio luasan dengan tipe Kolam

Perbandingan untuk luasan dengan ketinggian air pada kolam mengikuti persyaratan yang dipersyaratkan oleh F.G. Ogbe (2005), kolam tambak dengan luasan $0,02-0,06$ ha dengan kedalaman $1-1,5 \mathrm{~m}$

Berdasarkan rasio perbandingan faktor yang diperhatikan adalah sebaran dan komposisi tanah urugan untuk tanggul dan perimeter kolam tambak. Sebaran dan komposisi tanggul kolam tambak dapat dilihat pada Gambar 5 berikut.

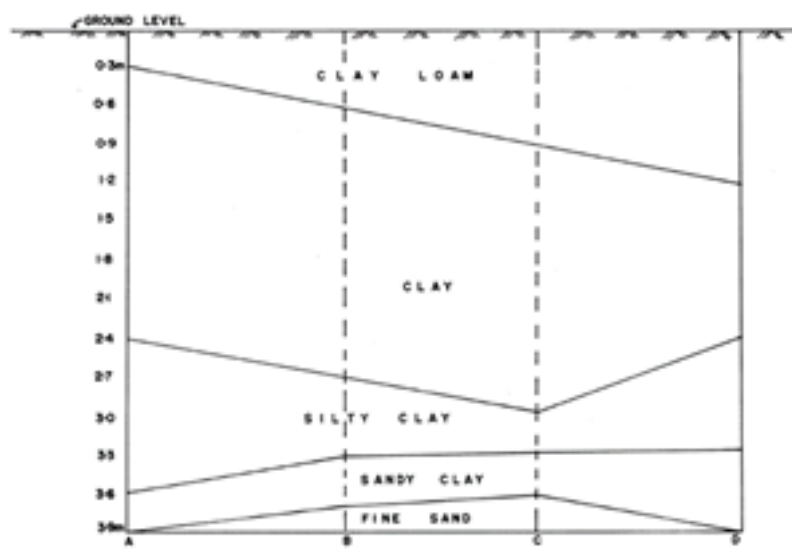

Gambar 5. Sebaran karakteristik tanah untuk dapat dipergunakan sebagai bahan tanggul dan perimeter kolam

Sumber: FAO, Fish Culture in Undrainable

Ponds - A manual for extension pond (2016)

\section{HASIL DAN PEMBAHASAN}

Berdasarkan hasil analisa yang dilakukan didapatkan hasil bahwa ketinggian pasang surut pada daerah lokasi studi berkisar antara
2,5 - 3 meter. Contoh tabel fluktuasi pasang surut dapat dilihat pada tabel 3 .

Pada awal perencanaan didapatkan dua buah alternatif pengambilan air untuk mengisi kolam tambak (Gambar 2 dan Gambar 3). Pada Alternatif 1 (Gambar 2) inlet merupakan saluran eksisting, pengirsian kolam dilakukan sesuai dengan pasang surut air laut secara normal, namun yang diatur hannya inlet dan outlet saja. Pada alternatif 2 (Gambar 3) pengambilan air langsung dari tengah laut dengan cara di bor kemudian untuk saluran pembawa menggunakan pipa untuk kemudian disalurkan ke kolam tambak.

Alternatif yang dipilih adalah alternatif 1 dengan penyesuaian ditambahkan perkuatan pada saluran outlet agar ketika pasang tidak menyebabkan bercampurnya inlet dan outlet Berdasarkan data yang diperoleh disimulasikan pasang surut yang terjadi pada perairan di Selat Madura dari tahun 2010 - 2017 dan informasi dari laboran di UPT dinas Perikanan Kota Probolinggo, maka diambil suatu kesimpulan bahwa pasang tertinggi yang pernah terjadi adalah 3 meter. Perencanaan tanggul yang direncanakan harus aman terhadap pasang dengan ketinggian 3 meter.

Pada pengamatan langsung dilapangan kisaran pasang surut adalah $3 \mathrm{~m}$, dan pada saat survei ketinggian pasang naik $1,75 \mathrm{~m}$. Pada stasiun dengan jarak $2 \mathrm{~km}$ dari pantai, kondisi air laut yang tercatat; Suhu air di permukaan berada pada $32^{\circ} \mathrm{C}$ dan pada titik $1 \mathrm{~m}$ dan $5 \mathrm{~m}$ seragam pada suhu $30^{\circ} \mathrm{C}$. Nilai salinitas untuk semua titik adalah $30 \mathrm{ppt}$. Transparansi air $2 \mathrm{~m}$ dan warna airnya berwarna hijau. Kedalaman air di lokasi adalah $5 \mathrm{~m}$.

Hasil pengamatan dan tabel pencatatan pasang surut yang telah diverifikasikan, selanjutnya menjadi patokan dasar untuk perencanaan dasar kolam tambak. Pada tahapan awal bentuk kontur petakan kolam tambak pada daerah lokasi studi dapat dilihat pada Gambar 6.

Berdasarkan hasil analisa untuk karakteristik tanah dan hasil pemeriksaan kondisi tanah yang ada pada lokasi studi maka dipilih beberapa kriteria untuk desain tanggul. Tanggul yang direncanakan terbagi menjadi; tanggul perimeter dan tanggul pemisah. 
Tabel 3. Prediksi dan Kondisi pasang surut serta aktifitas solunar

\begin{tabular}{|c|c|c|c|c|c|c|c|c|c|}
\hline \multirow{3}{*}{\multicolumn{2}{|c|}{$\begin{array}{l}\text { DAY } \\
\text { I Fil }\end{array}$}} & \multirow{2}{*}{\multicolumn{2}{|c|}{  }} & \multicolumn{5}{|c|}{ TIDSS FOR PASURUAW (MADURA STR) } & \multirow{3}{*}{$\begin{array}{l}\text { Solunia: } \\
\text { Activity } \\
\text { - }\end{array}$} \\
\hline & & & & \multirow{2}{*}{\begin{tabular}{|l|l|}
\multicolumn{1}{|c|}{1 TIDE } \\
$6: 19 \mathrm{~h}$ \\
$42.4 \mathrm{~m}$
\end{tabular}} & \multirow{2}{*}{\begin{tabular}{|l} 
20d TIDE \\
$\begin{array}{c}14: 50 \mathrm{~h} \\
71.0 \mathrm{~m}\end{array}$
\end{tabular}} & \multirow{2}{*}{$\begin{array}{l}\text { 3rd tide } \\
22: 01 \mathrm{~h} \\
1.9 \mathrm{~m}\end{array}$} & \multirow[t]{2}{*}{$4^{\text {th }}$ TIOE } & cocmpient & \\
\hline & & $4530 \mathrm{~h}$ & $=17: 27 \mathrm{~h}$ & & & & & $48 \quad 10 w$ & \\
\hline 2 & sat - & $45: 29 \mathrm{~h}$ & $=17: 27 \mathrm{~h}$ & $\begin{array}{l}1: 02 \mathrm{~h} \\
\nabla 1.5 \mathrm{~m}\end{array}$ & $\begin{array}{l}7: 22 \mathrm{~h} \\
42.5 \mathrm{~m}\end{array}$ & $\begin{array}{l}15: 26 \mathrm{~h} \\
70.9 \mathrm{~m}\end{array}$ & $\begin{array}{l}22: 16 \mathrm{~h} \\
12.0 \mathrm{~m}\end{array}$ & 59 average & $\rightarrow$ \\
\hline 3 & sun & $-5.29 \mathrm{~h}$ & $-17: 27 \mathrm{~h}$ & $\begin{array}{l}2=08 \mathrm{~h} \\
\mathbf{v} 1.4 \mathrm{~m}\end{array}$ & $\begin{array}{l}8: 15 \mathrm{~h} \\
42.6 \mathrm{~m}\end{array}$ & $\begin{array}{l}15: 57 \mathrm{~h} \\
70.8 \mathrm{~m}\end{array}$ & $\begin{array}{l}22: 33 \mathrm{~h} \\
42.0 \mathrm{~m}\end{array}$ & 71 high & $\Rightarrow$ \\
\hline & Mon & $4.528 \mathrm{~h}$ & . 17:27h & $\begin{array}{l}2.57 \mathrm{~h} \\
\times 1.3 \mathrm{~m}\end{array}$ & $\begin{array}{l}9: 01 \mathrm{~h} \\
\mathrm{~A} 2.7 \mathrm{~m}\end{array}$ & $\begin{array}{l}16: 26 \mathrm{~h} \\
70.7 \mathrm{~m}\end{array}$ & $\begin{array}{l}22: 54 \mathrm{~h} \\
A 2.1 \mathrm{~m}\end{array}$ & 81 high & $\rightarrow$ \\
\hline 5 & Tue & $4528 \mathrm{~h}$ & $17: 27 \mathrm{~h}$ & $\begin{array}{l}3: 30 \mathrm{~h} \\
\text { Y } 1.3 \mathrm{~m}\end{array}$ & $\begin{array}{l}0: 44 \mathrm{~h} \\
42.8 \mathrm{~m}\end{array}$ & $\begin{array}{l}16: 54 \mathrm{~h} \\
\times 0.7 \mathrm{~m}\end{array}$ & $\begin{array}{l}29: 17 \mathrm{~b} \\
422 \mathrm{~m}\end{array}$ & 89 high & $\rightarrow$ \\
\hline & Wed & $4.527 \mathrm{~h}$ & $-17: 27 \mathrm{~h}$ & $\begin{array}{l}4: 20 \mathrm{~h} \\
\nabla 1.2 \mathrm{~m}\end{array}$ & $\begin{array}{l}10: 24 \mathrm{~h} \\
42.8 \mathrm{~m}\end{array}$ & $\begin{array}{l}17: 23 \mathrm{~h} \\
70.7 \mathrm{~m}\end{array}$ & $\begin{array}{l}23: 42 \mathrm{~h} \\
42.3 \mathrm{~m}\end{array}$ & 95 very high & $\rightarrow \infty$ \\
\hline & Thu & $-5: 26 \mathrm{~h}$ & $=17: 27 \mathrm{~h}$ & $\begin{array}{l}5: 00 \mathrm{~h} \\
\text { v } 1.1 \mathrm{~m}\end{array}$ & $\begin{array}{l}11: 05 \mathrm{~h} \\
428 \mathrm{~m}\end{array}$ & $\begin{array}{l}17: 52 \mathrm{~h} \\
70.8 \mathrm{~m}\end{array}$ & & 97 very high & $\rightarrow \rightarrow$ \\
\hline 8 & Fri: & $-5.26 \mathrm{~h}$ & $=17: 26 h$ & $\begin{array}{l}0: 08 \mathrm{~h} \\
424 \mathrm{~m}\end{array}$ & $\begin{array}{l}5: 42 \mathrm{~h} \\
71.1 \mathrm{~m}\end{array}$ & $\begin{array}{l}11: 47 \mathrm{~h} \\
428 \mathrm{~m}\end{array}$ & $\begin{array}{l}18: 21 \mathrm{~h} \\
70.0 \mathrm{~m}\end{array}$ & 96 very high & $\rightarrow \infty$ \\
\hline ? & Sat & $-5.25 h$ & $=17: 26 h$ & $\begin{array}{l}0: 36 \mathrm{~h} \\
425 \mathrm{~m}\end{array}$ & $\begin{array}{l}0: 26 \mathrm{~b} \\
71.0 \mathrm{~m}\end{array}$ & $\begin{array}{l}12: 31 \mathrm{~h} \\
427 \mathrm{~m}\end{array}$ & $\begin{array}{l}18: 52 \mathrm{~h} \\
70.9 \mathrm{~m}\end{array}$ & 91 very nigh & $\rightarrow$ \\
\hline 10 & Sun & $+525 n$ & - 17:26h & $\begin{array}{l}1: 03 \mathrm{~h} \\
42.5 \mathrm{~m}\end{array}$ & $\begin{array}{l}7: 15 \mathrm{~h} \\
71.0 \mathrm{~m}\end{array}$ & $\begin{array}{l}13: 20 \mathrm{~h} \\
425 \mathrm{~m}\end{array}$ & $\begin{array}{l}19: 23 \mathrm{~h} \\
\mathrm{r} .1 \mathrm{~m}\end{array}$ & 82 high & $\rightarrow$ \\
\hline & Mon & $-5.24 \mathrm{~h}$ & $=17: 26 \mathrm{~h}$ & $\begin{array}{l}1: 33 \mathrm{~h} \\
42.6 \mathrm{~m}\end{array}$ & $\begin{array}{l}5: 11 \mathrm{~h} \\
\nabla 1.0 \mathrm{~m}\end{array}$ & $\begin{array}{l}14: 18 \mathrm{~h} \\
42.4 \mathrm{~m}\end{array}$ & $\begin{array}{l}19: 54 \mathrm{~h} \\
71.2 \mathrm{~m}\end{array}$ & 71 high & $\rightarrow \infty$ \\
\hline 12 & Tue & $45: 24 t$ & $=17: 26 \mathrm{~h}$ & $\begin{array}{l}2: 08 \mathrm{~h} \\
126 \mathrm{~m}\end{array}$ & $\begin{array}{l}9: 18 \mathrm{~h} \\
71.0 \mathrm{~m}\end{array}$ & $\begin{array}{l}15: 33 \mathrm{~h} \\
42.2 \mathrm{~m}\end{array}$ & $\begin{array}{l}20: 28 \mathrm{~h} \\
71.3 \mathrm{~m}\end{array}$ & 50 merage & $\Rightarrow \rightarrow$ \\
\hline 13 & wed & $45.23 \mathrm{n}$ & $17: 26 \mathrm{~h}$ & $\begin{array}{l}2.55 \mathrm{~h} \\
A 2.6 \mathrm{~m}\end{array}$ & $\begin{array}{l}10: 30 \mathrm{~h} \\
\mathbf{Y} 1.0 \mathrm{~m}\end{array}$ & $\begin{array}{l}17: 10 \mathrm{~h} \\
120 \mathrm{~m}\end{array}$ & $\begin{array}{l}21: 04 \mathrm{~h} \\
71.4 \mathrm{~m}\end{array}$ & 51 aversoe & $\Rightarrow$ \\
\hline 14 & Thu & $-5.23 \mathrm{~h}$ & $=17: 25 \mathrm{~h}$ & $\begin{array}{l}4: 07 \mathrm{~h} \\
42.6 \mathrm{~m}\end{array}$ & $\begin{array}{l}12: 10 \mathrm{~h} \\
70.9 \mathrm{~m}\end{array}$ & $\begin{array}{l}18: 57 \mathrm{~h} \\
420 \mathrm{~m}\end{array}$ & $\begin{array}{l}21.53 \mathrm{~h} \\
71.5 \mathrm{~m}\end{array}$ & 51 merape & 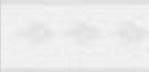 \\
\hline 15 & Fri: & $4522 \mathrm{~h}$ & $-17: 25 b$ & $\begin{array}{l}5: 39 \mathrm{~h} \\
42.6 \mathrm{~m}\end{array}$ & $\begin{array}{l}13: 31 \mathrm{~h} \\
\text { Y0.8 m }\end{array}$ & $\begin{array}{l}20: 32 \mathrm{~h} \\
120 \mathrm{~m}\end{array}$ & $\begin{array}{l}23: 33 \mathrm{~h} \\
71.5 \mathrm{~m}\end{array}$ & so anerage & $\rightarrow$ \\
\hline 16 & Sot & $45.21 \mathrm{~h}$ & $=17: 25 \mathrm{~h}$ & $\begin{array}{l}\text { 7:01 h } \\
\text { A } 2.7 \mathrm{~m}\end{array}$ & $\begin{array}{l}14: 32 \mathrm{~h} \\
\nabla 0.7 \mathrm{~m}\end{array}$ & $\begin{array}{l}21: 29 \mathrm{~h} \\
42.1 \mathrm{~m}\end{array}$ & & 71 high & $\Rightarrow$ \\
\hline 17 & Sun & $4521 \mathrm{~h}$ & $17: 25 h$ & $\begin{array}{l}1: 23 \mathrm{~h} \\
\nabla 1.5 \mathrm{~m}\end{array}$ & $\begin{array}{l}\text { : } 10 \mathrm{~h} \\
\mathrm{~A} 2 \mathrm{Tm}\end{array}$ & $\begin{array}{l}15: 10 \mathrm{~b} \\
\times 0.7 \mathrm{~m}\end{array}$ & $\begin{array}{l}22: 06 \mathrm{~b} \\
\$ 2.1 \mathrm{~m}\end{array}$ & 03 high & $\rightarrow$ \\
\hline & Mon & $45: 20 \mathrm{~h}$ & $-17: 25 \mathrm{~h}$ & $\begin{array}{l}2: 34 \mathrm{~b} \\
\nabla 1.4 \mathrm{~m}\end{array}$ & $\begin{array}{l}9: 00 \mathrm{~h} \\
42.8 \mathrm{~m}\end{array}$ & $\begin{array}{l}15: 50 \mathrm{~h} \\
70.7 \mathrm{~m}\end{array}$ & $\begin{array}{l}22: 36 \mathrm{~h} \\
422 \mathrm{~m}\end{array}$ & 92 very high & $\rightarrow \rightarrow$ \\
\hline 19 & Tue & $-5.20 \mathrm{~h}$ & $+17: 25 \mathrm{~h}$ & $\begin{array}{l}3.29 \mathrm{~h} \\
71.3 \mathrm{~m}\end{array}$ & $\begin{array}{l}10: 01 \mathrm{~h} \\
\mathrm{~A} 28 \mathrm{~m}\end{array}$ & $\begin{array}{l}16: 35 \mathrm{~h} \\
70.7 \mathrm{~m}\end{array}$ & $\begin{array}{l}23: 04 \mathrm{~h} \\
42.3 \mathrm{~m}\end{array}$ & 08 very high & $\rightarrow \rightarrow$ \\
\hline 20 & Wed & $4.5 .19 \mathrm{~h}$ & 17:25h & $\begin{array}{l}4: 17 \mathrm{~h} \\
\nabla 1.2 \mathrm{~m}\end{array}$ & $\begin{array}{l}10: 48 \mathrm{~h} \\
428 \mathrm{~m}\end{array}$ & $\begin{array}{l}17: 00 \mathrm{~h} \\
70.0 \mathrm{~m}\end{array}$ & $\begin{array}{l}23: 29 \mathrm{~b} \\
42.4 \mathrm{~m}\end{array}$ & 29 very high & $\Rightarrow \rightarrow$ \\
\hline 29 & The & A $5: 19 \mathrm{n}$ & $+17: 24 \mathrm{~h}$ & $\begin{array}{l}5: 01 \mathrm{~h} \\
\nabla 1.1 \mathrm{~m}\end{array}$ & $\begin{array}{l}11: 31 \mathrm{~h} \\
427 \mathrm{~m}\end{array}$ & $\begin{array}{l}17: 41 \mathrm{~b} \\
70.9 \mathrm{~m}\end{array}$ & $\begin{array}{l}23: 59 \mathrm{~b} \\
425 \mathrm{~m}\end{array}$ & 96 very high & $\Rightarrow \rightarrow$ \\
\hline 22 & Fit & A 5.18 h & $=17: 24 \mathrm{~h}$ & $\begin{array}{l}5: 44 \mathrm{~h} \\
\nabla 1.0 \mathrm{~m}\end{array}$ & $\begin{array}{l}12: 13 \mathrm{~h} \\
42.6 \mathrm{~m}\end{array}$ & $\begin{array}{l}18: 12 \mathrm{~h} \\
\nabla 1.0 \mathrm{~m}\end{array}$ & & 00 high & $\rightarrow-$ \\
\hline 23 & Sat & A $5.17 \mathrm{~h}$ & $-17: 24 \mathrm{~h}$ & $\begin{array}{l}0: 14 \mathrm{~h} \\
425 \mathrm{~m}\end{array}$ & $\begin{array}{l}6: 27 \mathrm{~h} \\
71.0 \mathrm{~m}\end{array}$ & $\begin{array}{l}12.54 \mathrm{~h} \\
425 \mathrm{~m}\end{array}$ & $\begin{array}{l}18: 42 \mathrm{~h} \\
71.1 \mathrm{~m}\end{array}$ & $80 \quad$ high & $\Rightarrow$ \\
\hline 24 & Sun & $45: 17 n$ & $-17: 24 h$ & $\begin{array}{l}0: 34 \mathrm{~h} \\
426 \mathrm{~m}\end{array}$ & $\begin{array}{l}7: 11 \mathrm{~h} \\
71.1 \mathrm{~m}\end{array}$ & $\begin{array}{l}13: 37 \mathrm{~h} \\
42.4 \mathrm{~m}\end{array}$ & $\begin{array}{l}19: 10 \mathrm{~h} \\
71.2 \mathrm{~m}\end{array}$ & 70 high & $x^{2}=y^{2}$ \\
\hline 25 & Mon & $\Delta 5.16 \mathrm{~h}$ & $-17: 24 h$ & $\begin{array}{l}0.55 \mathrm{~h} \\
4.20 \mathrm{~m}\end{array}$ & $\begin{array}{l}\text { 7:58 h } \\
\text { v } 1.1 \mathrm{~m}\end{array}$ & $\begin{array}{l}14: 27 \mathrm{~h} \\
42.2 \mathrm{~m}\end{array}$ & $\begin{array}{l}19: 35 \mathrm{~h} \\
\mathbf{v} .1 .4 \mathrm{~m}\end{array}$ & 58 werage & $\rightarrow \quad-\quad$ \\
\hline 26 & Tue & A $5: 16 \mathrm{~h}$ & $=17: 24 \mathrm{~h}$ & $\begin{array}{l}1: 19 \mathrm{~h} \\
42.6 \mathrm{~m}\end{array}$ & $\begin{array}{l}\text { 8.52h } \\
7.2 \mathrm{~m}\end{array}$ & $\begin{array}{l}15: 32 \mathrm{~h} \\
421 \mathrm{~m}\end{array}$ & $\begin{array}{l}19: 56 \mathrm{~h} \\
\nabla 1.5 \mathrm{~m}\end{array}$ & $46 \quad 10 \mathrm{w}$ & $\rightarrow$ \\
\hline 27 & Wed & $-5.15 \mathrm{n}$ & $-17: 24 h$ & $\begin{array}{l}1: 49 \mathrm{~h} \\
426 \mathrm{~m}\end{array}$ & $\begin{array}{l}10: 00 \mathrm{~h} \\
>1.2 \mathrm{~m}\end{array}$ & $\begin{array}{l}17: 06 \mathrm{~h} \\
12.0 \mathrm{~m}\end{array}$ & $\begin{array}{l}20: 06 \mathrm{~h} \\
\nabla 1.5 \mathrm{~m}\end{array}$ & 37 low & $\rightarrow-$ \\
\hline 28 & The & $45: 15 \mathrm{~h}$ & $17: 23 \mathrm{~h}$ & $\begin{array}{l}\text { 2:31 h } \\
\text { A } 2.5 \mathrm{~m}\end{array}$ & $\begin{array}{l}11: 33 \mathrm{~h} \\
\mathbf{1} 1.2 \mathrm{~m}\end{array}$ & & & 35 low & $\Rightarrow 0$ \\
\hline 29 & $F i$ & A $5: 14 \mathrm{~h}$ & - $17: 23 \mathrm{~h}$ & $\begin{array}{l}3: 35 \mathrm{~h} \\
425 \mathrm{~m}\end{array}$ & $\begin{array}{l}13: 03 \mathrm{~h} \\
\mathrm{~T} 1.1 \mathrm{~m}\end{array}$ & & & $2^{30}$ & $\rightarrow \rightarrow$ \\
\hline 30 & Set: & $45.14 \mathrm{~h}$ & $17: 23 \mathrm{~h}$ & $\begin{array}{l}5: 12 \mathrm{~h} \\
124 \mathrm{~m}\end{array}$ & $\begin{array}{l}14: 02 \mathrm{~h} \\
71.0 \mathrm{~m}\end{array}$ & $\begin{array}{l}21: 44 \mathrm{~h} \\
42.1 \mathrm{~m}\end{array}$ & & 46 low & 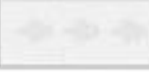 \\
\hline
\end{tabular}




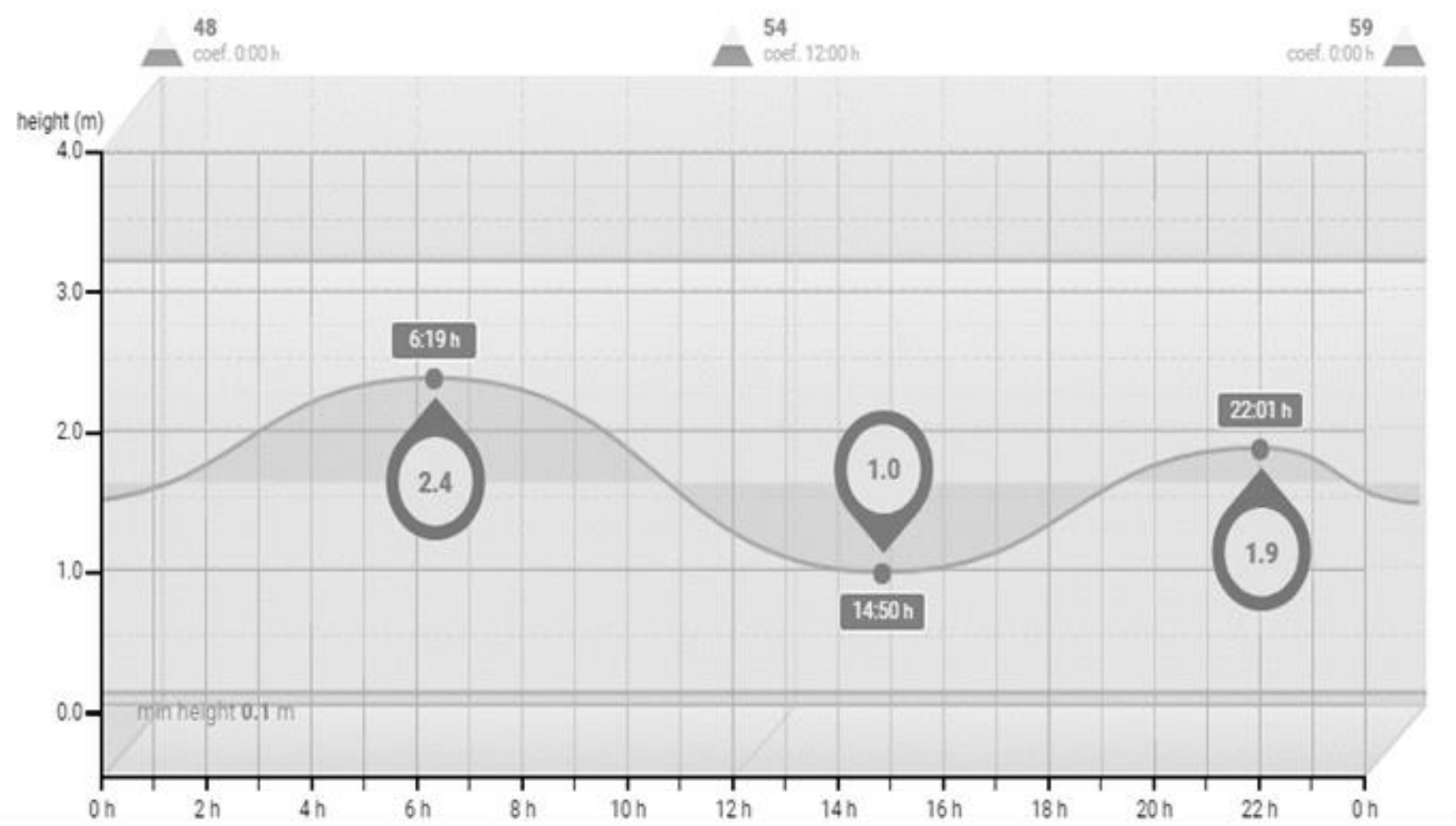

Gambar 6. Grafik Fluktuasi Pasang Surut untuk Perencanaan Tanggul Kolam

Sumber: http://www.tides4fishing.com/as/west-indonesia/kalianget-madura-island\#_tide_table

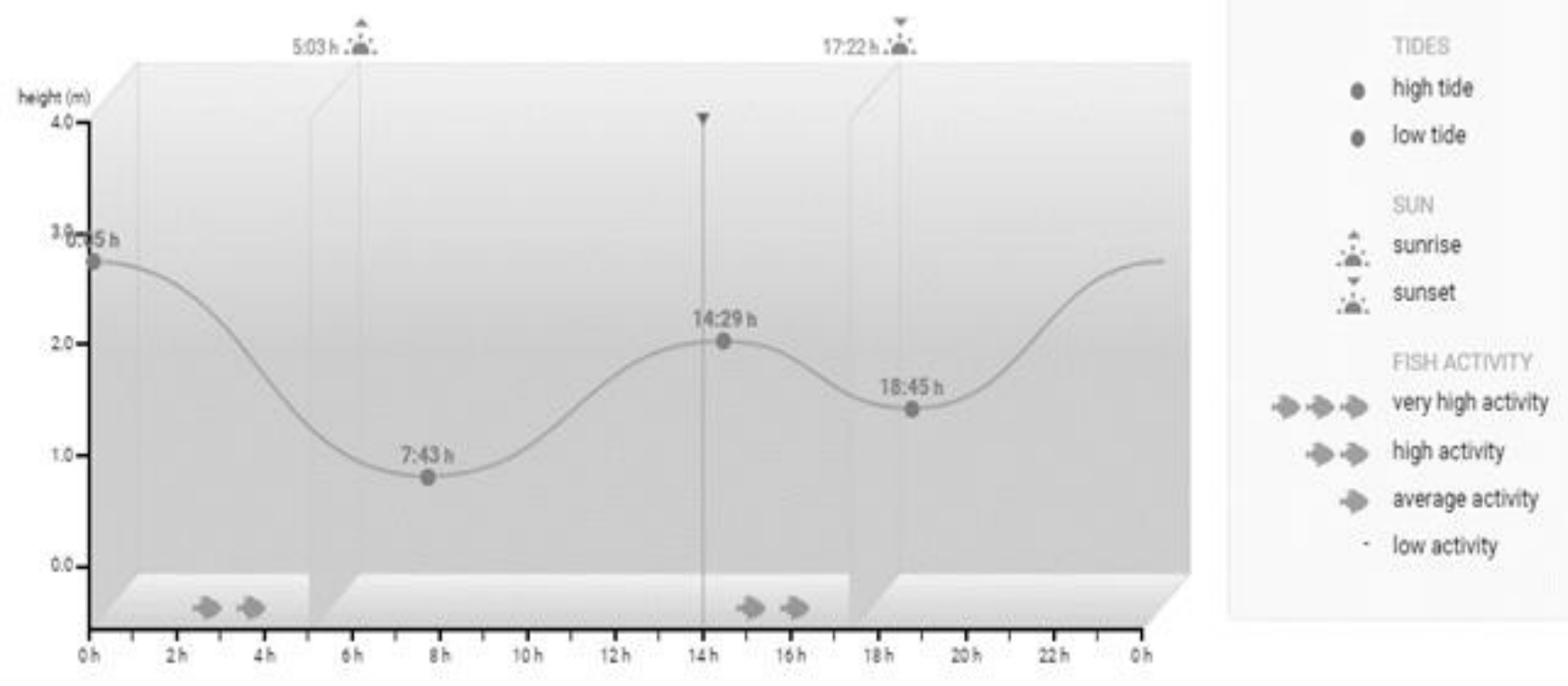

Gambar 7. Perhitungan yang dipergunakan untuk desain tanggul

Sumber: $\quad$ http://www.tides4fishing.com/as/west-indonesia/kalianget-madura-island\#_tide_table 




Gambar 8. Hasil pemetaan dan pengukuran petakan tambak

Sumber: Pengukuran Lapangan

Menurut Sugianto (2009) semakin landai suatu konstruksi maka akan didapatkan tanggul dan kolam yang cukup stabil saat pasang tertinggi. Kondisi tersebut tentunya akan berpengaruh terhadap volume timbunan tanah untuk tanggul yang semakin besar. Tanggul optimum dipilih untuk memberikan jalan tengah terhadap volume timbunan dan kekuatan serta keamanan terhadap pasang surut air laut.

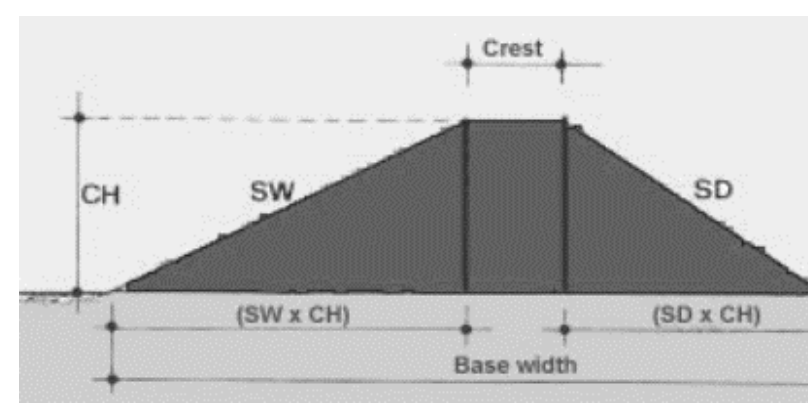

Gambar 9. Perhitungan yang dipergunakan untuk desain tanggul

Sumber: Yo, Kyung H. And Claude E. Boyd (1994)

Untuk desain tanggul pematang yang dipergunakan dapat dilihat pada Gambar 10.

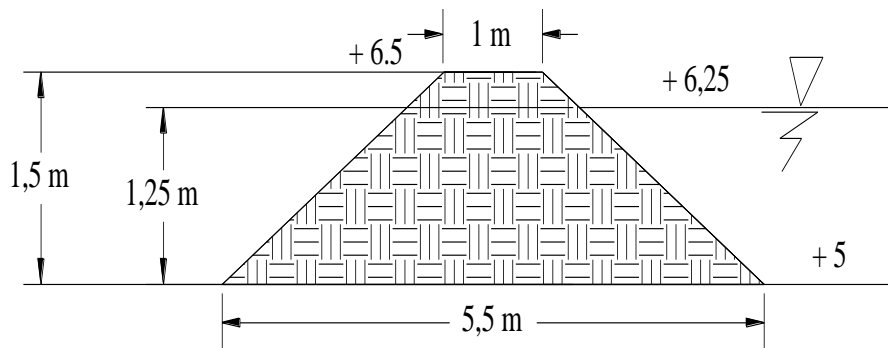

Gambar 10. Hasil analisa tanggul pematang tambak Probolinggo

Sumber: Analisa

Desain untuk tanggul perimeter (pelindung dari pasang surut untuk kolam tambak) dapat dilihat pada Gambar 11.

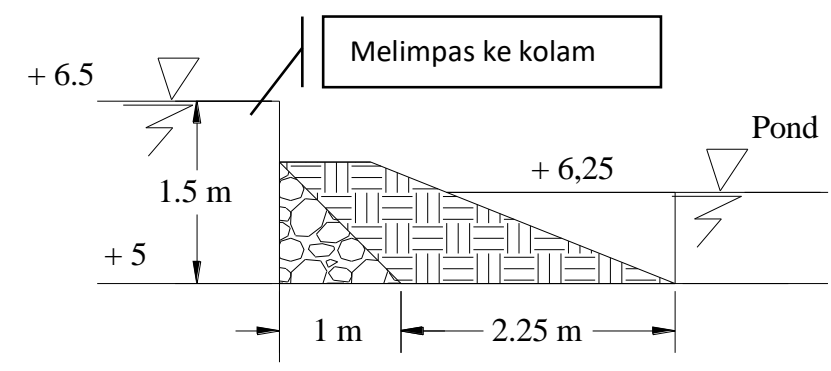

Gambar 11. Kondisi Eksisting Tanggul

Perimeter saat pasang tinggi tertinggi

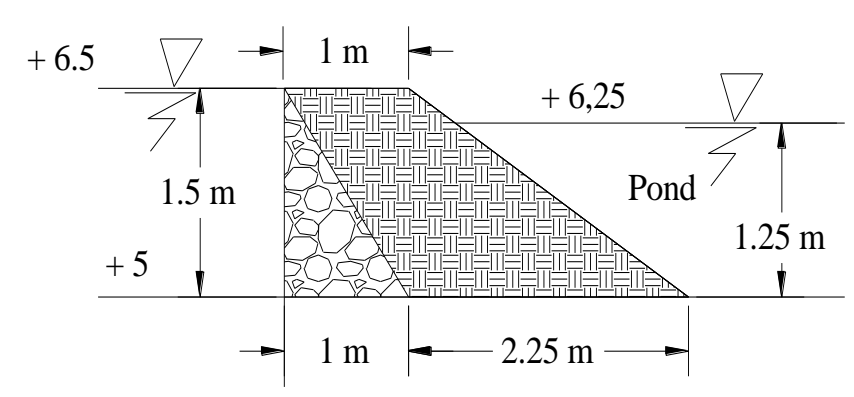

Gambar 12. Hasil analisa tanggul perimeter tambak Probolinggo saat pasang tinggi tertinggi (dengan tinggi jagaan $0,3 \mathrm{~m}$ )

Sumber: Analisa

Sebagai air pembuangan kolam tambak pada tahap 1, digunakan sistem pembuangan dengan memanfaatkan sistem under-drain. Konsep under-drain adalah sistem pembuangan air kolam dengan penggantian air pada lapisan paling bawah kolam, sehingga kondisi penyinaran dan turbulensi aliran bisa diminimalisir. Pemilihan desain tersebut dimaksudkan agar udang lebih nyaman pada kondisi tersebut. 


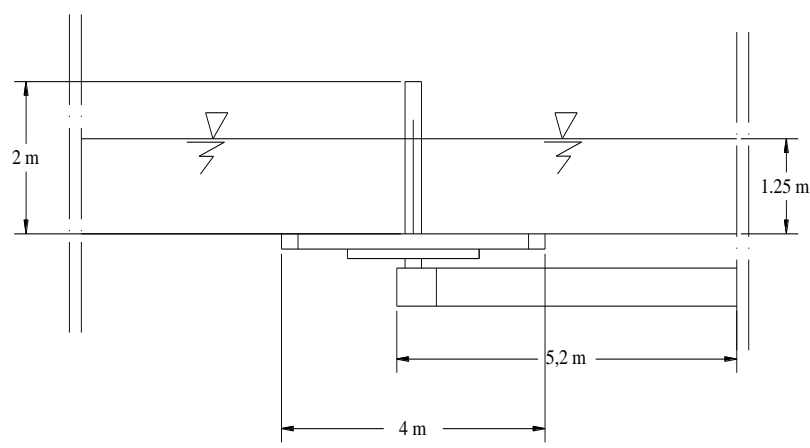

Gambar 13. Hasil analisa tanggul perimeter tambak Probolinggo



Gambar 14. Pembagian Petakan Kolam Tambak

Sumber: Analisa 


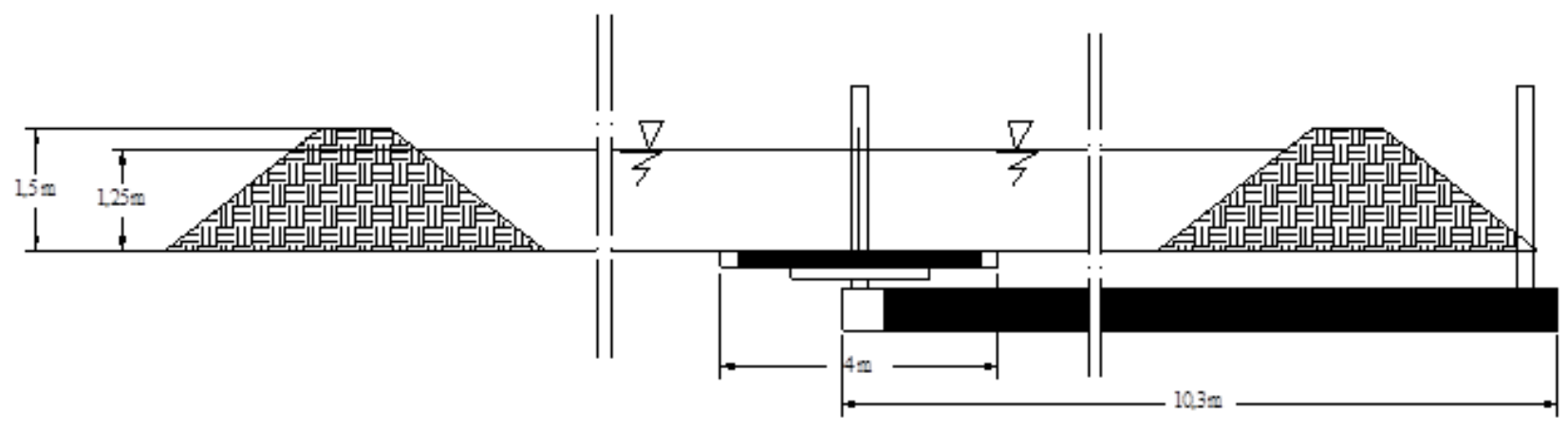

Gambar 15. Potongan Melintang Kolam Tambak Sumber: Analisa

Untuk pasang tinggi tertinggi rata-rata (3 m) kondisi sudah dapat dimasukkan dalam kategori aman. Sedangkan untuk pasang tertinggi harian (setinggi $2,5 \mathrm{~m}$ ) masih aman. Pembagian petakan kolam tambak menjadi 4 bagian kolam dengan luasan sebesar 31,5 m x
31,5 m, sehingga pada luasan tambak keseluruhan menjadi seluas 5285,29 $\mathrm{m}^{2}$.

Pembagian petakan kolam tambak dapat dilihat pada Gambar 14, untuk potongan melintang dapat dilihat pada Gambar 15.

Tabel 4. Kriteria Desain Tanggul Kolam Tambak

\begin{tabular}{|c|c|c|c|c|}
\hline No. & Keterangan & $\begin{array}{l}\text { Kriteria Luasan } \\
\text { Kolam }\end{array}$ & Luasan Desain $\left(\mathrm{m}^{2}\right)$ & Kode Kolam \\
\hline 1 & Kolam Aklamatisasi & $4-8 m^{2}$ & 8,000 & \\
\hline 2 & Kolam Pembenihan & $1 \%$ luasan & 52,853 & B \\
\hline 3 & Kolam Transisi & $10 \%$ luasan total & 528,529 & C \\
\hline 4 & Kolam Produksi & $80 \%$ luasan total & 4246,658 & D \\
\hline 5 & $\begin{array}{l}\text { Kolam Permanen (dengan } \\
\text { pintu) }\end{array}$ & $1,5 \%$ luasan total & 79,279 & \multirow{2}{*}{ A } \\
\hline 6 & $\begin{array}{c}\text { Kolam penumbuhan } \\
\text { makanan }\end{array}$ & $7 \% \mathrm{~m}^{2}$ & 369,970 & \\
\hline & & Total & 5285,29 & \\
\hline
\end{tabular}

Sumber: Analisa

Berdasarkan pembagian kolam maka luasan pembagian diatur sesuai dengan Tabel 4.

\section{KESIMPULAN}

Desain kolam untuk irigasi tambak udang terbuka dengan melibatkan pasang surut memberikan tantangan tersendiri, hal ini dikarenakan dengan adanya intervensi pasang surut yang terjadi kemungkinan gangguan untuk komoditas udang sangat besar. Pada model kolam direncanakan dimodifikasi untuk tanggul perimeter (tanggul pelindung) dengan tinggi setinggi $0,5 \mathrm{~m}$. Dengan melihat tren data pasang surut yang terjadi penambahan setinggi $0,5 \mathrm{~m}$ dirasa sudah sesuai. Secara umum pasang tertinggi setinggi $2,5 \mathrm{~m}$, untuk tingkat keamanan maka dipergunakan pasang tinggti tertinggi setinggi $3 \mathrm{~m}$ untuk faktor keamanan 
agar pasang tertinggi tidak melimpas masuk ke dalam kolam.

Untuk kebutuhan irigasi tambak diperlukan desain petakan tambak yang sesuai khususnya untuk budidaya udang, pada luasan paling besar adalah yang dipergunakan untuk kolam produksi, hal ini disebabkan karena hampir semua udang berada pada kolam ini.

\section{DAFTAR PUSTAKA}

Anh Lam Nguyen, Minh Hoang Truong, Johan AJ Verreth, Rik Leemans, Roel H Bosma and Sena S De Silva. Exploring the climate change concerns of striped catfish producers in the Mekong Delta, Vietnam. SpringerPlus: 2015.

Anh Lam Nguyen, Minh Hoang Truong, Johan AJ Verreth, Rik Leemans, Roel H Bosma and Sena S De Silva. Simulated Impacts of Climate Change on Current Farming Locations of Striped Catfish (Pangasianodon hypophthalmus; Sauvage) in the Mekong Delta, Vietnam. Springers: 2014.

Cruz, C.R Dela. Fishpond Engineering: A Technical Manual For Smalland Mediumscale Coastal Fish Farms In Southeast Asia. FAO 2015.
Kim T. Tran-Ngoc a,c, Johan W. Schrama a, Mai T.T. Le a, Thinh H. Nguyen c, Arjen J. Roem a,b, Johan A.J Verreth. Salinity and diet composition affect digestibility and intestinal morphology in Nile tilapia (Oreochromis niloticus). Elsevier: 2016

https://www.researchgate.net/publication/3113 58646_Salinity_and_diet_composition _affect_digestibility_and_intestinal_m orphology_in_Nile_tilapia_Oreochrom is_niloticus

Sugianto, Denny Nugroho. Kajian Kondisi Hidrodinamika (Pasang Surut, Arus, Dan Gelombang) di Perairan Grati Pasuruan, Jawa Timur. UNDIP : Semarang 2009.

Ogbe, F.G., Taicvva K.T., Adegoye M.S. And Akoh I.L. The Hyprology Of A Small Fish Pond At The University Of Agriculture, Makurdi Experimental Fish Farm. Benue State. 2005

Yo, Kyung H. And Claude E. Boyd. Hydrology and Water Supply for Pond Aquaculture. Springer Science+Business Media Dordrecht: 1994. 